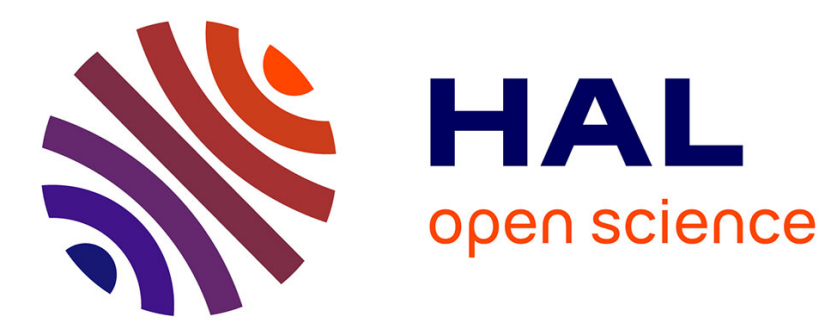

\title{
A Probabilistic Approach for Fragmentation of Brittle Materials under Dynamic Loading
}

\author{
Christophe Denoual, Gilles Barbier, François Hild
}

\section{To cite this version:}

Christophe Denoual, Gilles Barbier, François Hild. A Probabilistic Approach for Fragmentation of Brittle Materials under Dynamic Loading. Comptes rendus de l'Académie des sciences. Série IIb, Mécanique, 1997, 325 (12), pp.685-691. 10.1016/S1251-8069(97)82333-0 . hal-02342261

\section{HAL Id: hal-02342261 https://hal.science/hal-02342261}

Submitted on 31 Oct 2019

HAL is a multi-disciplinary open access archive for the deposit and dissemination of scientific research documents, whether they are published or not. The documents may come from teaching and research institutions in France or abroad, or from public or private research centers.
L'archive ouverte pluridisciplinaire HAL, est destinée au dépôt et à la diffusion de documents scientifiques de niveau recherche, publiés ou non, émanant des établissements d'enseignement et de recherche français ou étrangers, des laboratoires publics ou privés. 


\title{
A probabilistic approach for fragmentation of brittle materials under dynamic loading
}

\author{
Christophe DENOUAL, Gilles BARBIER and François HILD
}

C. D. : Département Matériaux en Conditions Sévères, DGA/CREA, 16 bis, avenue Prieur de la Côte d'Or, 94114 Arcueil cedex ;

G. B. : Département MTC, EDF/DER, Centre des Renardières, BP 1, Écuelles, 77250 Moret-sur-Loing ;

F. H. : Laboratoire de Mécanique et Technologie, ENS de Cachan/CNRS/Université Paris-VI, 61, avenue du Président-Wilson, 94235 Cachan cedex, France.

\begin{abstract}
Dynamic loadings produce high stress waves leading to the fragmentation of brittle materials such as ceramics. The main mechanism used to explain the change of the number of fragments with stress rate is an obscuration phenomenon. After the presentation of a probabilistic approach, the evolution of the number of nucleated flaws and a damage model are derived.
\end{abstract}

Keywords: boolean random function / brittle materials / damage / fragmentation / impact / obscuration / probabilistic approach

\section{Approche probabiliste de la fragmentation de matériaux fragiles sous chargement dynamique}

Résumé. Une sollicitation dynamique ou par explosions de matériaux fragiles conduit à leur fragmentation. Dans cette note, un modèle de fragmentation dynamique pour matériaux fragiles est proposé sur une base probabiliste. Un modèle d'endommagement est également discuté. Le principal mécanisme invoqué pour expliquer la variation en nombre de fragments est un phénomène d'occultation des défauts entre eux.

Mots clés : fonction booléenne aléatoire / matériaux fragiles / endommagement / fragmentation / impact / occultation / approche probabiliste

\section{Version française abrégée}

La fragmentation est souvent observée dans les matériaux fragiles sollicités dynamiquement, soit par impact sur des blindages en céramique, soit par explosion de structures coques. Dans cette note, on s'intéresse à l'endommagement par fissuration en mode I de structures fragiles, en étudiant la probabilité de rupture des défauts en fonction des défauts environnants déjà rompus. En effet, la rupture d'un défaut entraîne une relaxation locale des contraintes (fig. $l$ ) qui peut interdire la rupture (ou occulter) d'autres défauts. L'interaction entre les défauts susceptibles de rompre et cette zone d'occul- 
tation permet de comprendre pourquoi une fissure peut (ou ne peut pas) s'amorcer sur un défaut. Lorsque le défaut considéré est loin du défaut déjà rompu, la contrainte locale n'est pas affectée. En revanche, quand le défaut est dans la zone affectée par la nucléation du premier et que la contrainte locale est décroissante, aucun amorçage ne peut alors se produire dans cette zone. Ces interactions sont décrites dans un graphe «espace-temps » où l'on représente en abscisse l'espace (dont la dimension $n$ est égale à 1,2 ou 3 ) et où l'ordonnée représente le temps (fig. 2). Dans l'exemple proposé, les défauts 1 et 2 rompent et produisent des zones d'occultation qui interdisent la nucléation des défauts 3 et 4. Pour définir les zones dans lesquelles les défauts peuvent rompre, il est préférable d'inverser le problème en définissant les conditions de non-occultation pour un défaut donné, i.e. de regarder dans le passé d'un défaut susceptible de rompre si un défaut existe dans son horizon (fig. 3). Le nombre moyen de défauts susceptibles de rompre (noté $\mu_{\mathrm{t}}$ et supposé poissonnien) peut être divisé en un ensemble de défauts occultés, noté $\mu_{0}$, et un ensemble de défauts rompus, noté $\mu_{\mathrm{b}}$ [éq. (1)]. La densité moyenne de défauts $\lambda$ est définie par (2). L'équation différentielle (3) donne l'évolution de la variable $\lambda_{b}$ en fonction de $\lambda_{t}$ en connaissant la probabilité de non-occultation $P_{\text {no }}$ (définie en (4), où $Z_{i}^{(n)}$ est une mesure de la zone d'interaction au temps $t$ pour un défaut critique à $T$ ). La variable $\lambda_{\mathrm{b}}$ est proche de $\lambda_{1}$ au début du chargement, mais devient par la suite très inférieure à $\lambda_{t}$ pour $T$ grand. Cette approche est confortée par l'existence d'une écriture identique utilisant le modèle d'iles booléennes (Serra, 1982 ; Jeulin, 1985). La probabilité d'être dans une zone non occultée s'exprime alors par l'intermédiaire de la taille moyenne des zones occultées au temps $T$, notée $\mathscr{M}^{(n)}(T)$ [éqs. (5) et (6)].

On suppose les zones d'interactions homothétiques (Bluhm, 1969 ; Freund, 1972) et être de la forme (7) avec $k \in] 0,1]$ un paramètre de forme et $C$ la célérité des ondes. La variable $\mu_{\imath}$ peut être estimée à partir d'une distribution en loi puissance à deux paramètres (8), où $m$ est le module de Weibull et $S_{0}$ un paramètre d'échelle relatif à la zone de référence de mesure $Z_{0}^{(n)}$. Pour une vitesse de contrainte $\sigma$ constante, une écriture adimensionnée de la densité de défauts $\bar{\lambda}$, du temps $\bar{T}$, de la mesure de zone $\bar{Z}^{(n)}$ et de la contrainte $\bar{\sigma}$ est proposée à l'aide de (9), où l'indice $c$ indique une grandeur caractéristique.

Une première application est la densité de défauts rompus dont l'évolution est donnée en (10) dans le cas d'une vitesse de contrainte $\dot{\sigma}$ constante, où $\gamma$ est la fonction gamma incomplète et $\left(\begin{array}{c}m+n \\ m\end{array}\right)=(m+n) ! /(m ! n !)$. Dans les résultats présentés sur la figure 4 , le phénomène de saturation n'est dépendant que du module de Weibull $m$ et de la dimension de l'espace $n$.

Une deuxième application est la définition d'une variable d'endommagement dans le cadre de la mécanique des milieux continus. En effet, sur une zone représentative, on peut écrire $D=1-P_{\mathrm{no}}$. Il apparaît que l'équation différentielle proposée par Grady et Kipp (1980) pour décrire l'évolution de la variable d'endommagement est le premier ordre de l'équation (4). L'évolution de $D$ est alors décrite par (11) en utilisant (4) et (7). En remarquant que l'évolution de $D$ (de 0 à 1) est limitée à un intervalle de temps de $t_{\mathrm{c}}$, la mesure de la zone représentative associée à $D$ devient égale à la mesure de la zone caractéristique $Z_{c}^{(n)}$. Pour une vitesse de contrainte $\dot{\sigma}$ constante, une expression de $D$ est définie par (12) à l'aide de (11) et (8). Une contrainte macroscopique $\Sigma$ peut être définie (en opposition à la contrainte locale ou effective $\sigma$ ) par $\sigma=\Sigma /(1-D)$. Cette contrainte est maximale $(\mathrm{d} \Sigma / \mathrm{d} \sigma=0)$ pour la valeur donnée en (13).

\section{Introduction}

A probabilistic fragmentation analysis can be performed on brittle structures submitted to high tensile stress rate loading. Dynamic fragmentation occurs, for example, in an impacted ceramic. In the 
bulk of the ceramic, damage in tension is observed when the hoop stress induced by the radial motion is sufficiently large to generate fracture in mode I initiating on micro-defects such as porosities or inclusions. Another situation is the explosion of 2D structures (impact on plate, exploding spherical shell) which generates a wide range of fragments. In this note, it is proposed to model fragmentation in brittle materials for which a time-dependent microscopic stress is applied. To study the fragmentation problem, it is assumed that the macroscopic stress state is homogeneous throughout the whole body. When a fracture is initiated in mode $I$, the local stress state is modified around the crack by a stress relief wave which is a complex function of time, crack velocity and stress wave celerity ( fig. I). To understand why a crack nucleates, one has to model the interaction of the zone (i.e., volume, surface or length) affected by the stress relief and other defects that would nucleate. The behavior of a flaw around a nucleated one can be described by two different cases:

- the flaw is far from the nucleated one and the microscopic stress state is not affected;

- the flaw is in the interaction zone and the microscopic tensile stress is decreasing, i.e., no cracks are emanating from this potential initiation site.

A third case may occur in which the flaw is in the affected zone but the local tensile stress increases, i.e., initiation may occur. It is assumed that this case is insignificant in this problem.

Fig. 1. - Relaxation around a propagating crack at time $T$ and $T+\Delta T$.

Fig. 1. - Relaxation autour d'une fissure qui se propage d un instant $T$ et $T+\Delta T$.

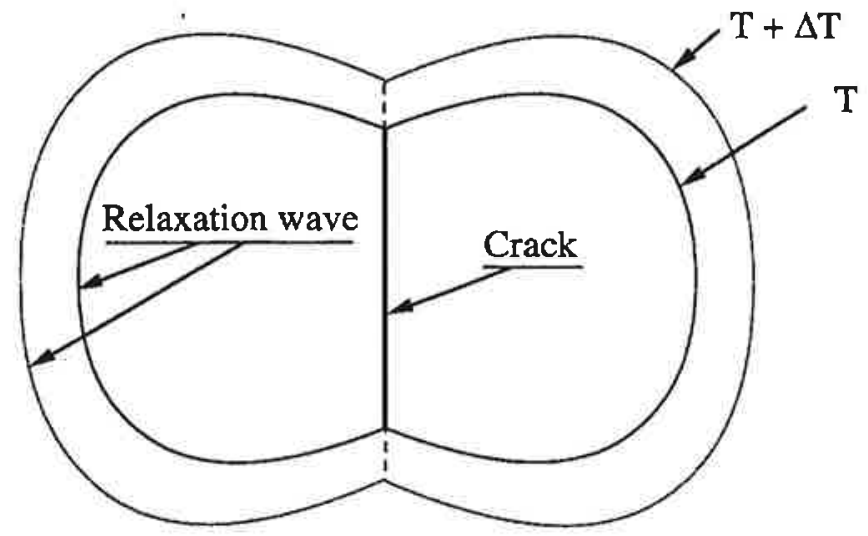

\section{Probabilistic approach}

The direction of the microscopic maximum principal stress is assumed to be constant, which allows to use $\sigma=\max \left[\sigma_{1}, \sigma_{2}, \sigma_{3}\right]$ instead of the stress tensor as an equivalent failure stress. The flaw nucleation can be represented on a space-time graph (fig. 2). The space locations of the defects are represented in a simple abscissa (instead of a three-, two- or one-dimensional representation) of an $x-y$ graph where the $y$-axis represents the time (or stress) to failure of a given defect. The first crack nucleation occurs at time $T_{1}$ (corresponding to a stress $\sigma\left[T_{1}\right]$ ) at the space location $M_{1}$ and produces an 'obscured zone' $Z_{\mathrm{i}}\left(T-T_{1}\right)$ increasing with time. At time $T_{2}$ (corresponding to a stress $\left.\sigma\left[T_{2}\right]>\sigma\left[T_{1}\right]\right)$ a second defect nucleates in a non-affected zone and produces its own obscured zone. The third and fourth defects do not nucleate because they are obscured by the first and both first and second defects, respectively. It is worth noting that the stress levels in overlapping obscured zones cannot be greater than the highest initiation stress associated to the considered obscured zones. The space-time graph is composed of the union of obscured zones in which no flaws can initiate and the complementary zone in which defects can nucleate. Because different obscured 


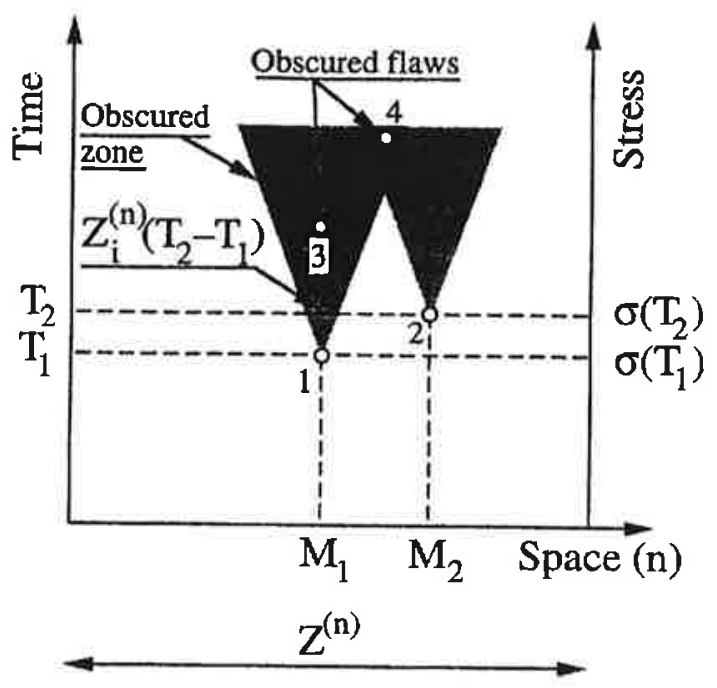

Fig. 2. - Fragmentation and obscuration phenomena.

Fig. 2. - Phénomènes de fragmentation et d'obscurcissement.

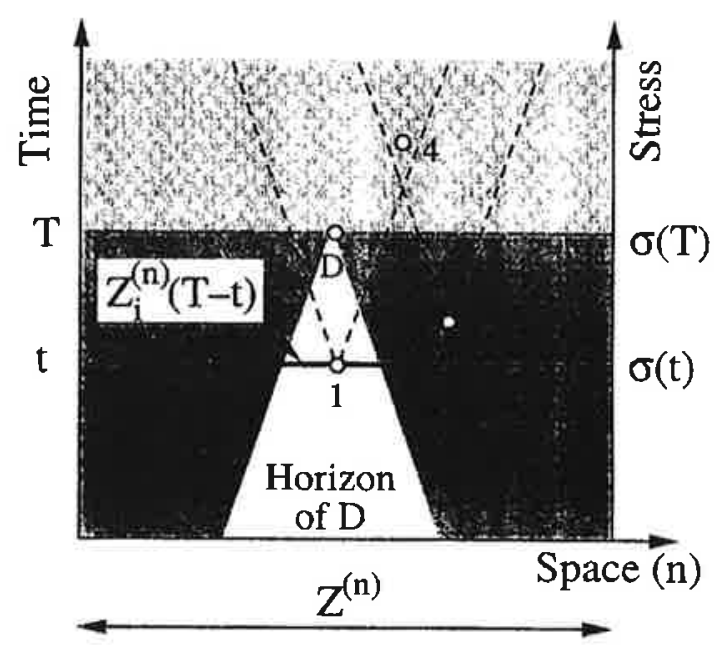

Fig. 3. - Schematic of the horizon of a defect D.

Fig. 3. - Schéma de l'horizon d'un défaut $D$.

zones may overlap (i.e., a flaw can be obscured by one or more cracks), it is preferable to define the conditions of non-obscuration for a given defect by examining the inverse problem. It consists of considering the past history of a defect that would break at a time $T$. The defect will break if no defects exist in its horizon. For a given flaw $\mathrm{D}$ its horizon is defined as a space-time zone in which a defect will always obscure $\mathrm{D}(\mathrm{fg}$. 3). Outside the horizon a defect will never obscure D.

The flaw distribution can be split into two parts and the average number of broken flaws can be written as

$$
\mu_{\mathrm{b}}\left(T, Z^{(n)}\right)=\mu_{\mathrm{c}}\left(T, Z^{(n)}\right)-\mu_{\mathrm{o}}\left(T, Z^{(n)}\right)
$$

where $\mu\left(T, Z^{(n)}\right)$ denotes the mean number of flaws that may break in a zone of measure $Z^{(n)}$ (i.e., volume $(n=3)$, surface $(n=2)$ or length $(n=1))$ for a stress greater than or equal to $\sigma(T)$. The subscripts indicate the effectively broken flaws $(b)$, the obscured flaws $(o)$, and the total number of flaws able to break $(t)$. The number of flaws $\mu$ is normalized by $Z^{(n)}$ to define the average flaw density $\lambda(T)$

$$
\mu\left(T, Z^{(n)}\right)=Z^{(n)} \lambda(T) .
$$

Furthermore, we assume that the distribution of total flaws is modeled by a Poisson point process of intensity $\mu_{\mathrm{t}}$. New cracks will initiate only if the defect exists in the considered zone and if no defects exist in its horizon so that

$$
\frac{\mathrm{d} \lambda_{\mathrm{b}}}{\mathrm{d} t}(T)=\frac{\mathrm{d} \lambda_{\mathrm{t}}}{\mathrm{d} t}(T) P_{\mathrm{no}}(T) \quad \text { with } \quad \lambda_{\mathrm{b}}(0)=\lambda_{\mathrm{l}}(0)=0
$$

where $P_{\text {по }}$ is the probability that no defects exist in the horizon. An equivalent form for equation (3) can be found in Jeulin (1985). The variable $P_{\text {no }}$ can be split into an infinity of events defined by the probability of finding at $t$ a new defect during a time step $\mathrm{d} t$ in an interaction zone $Z_{\mathrm{i}}^{(n)}(T-t)$. 
This probability increment is written by using a Poisson point process of intensity $\mathrm{d} \lambda_{t} / \mathrm{d} t$. Those independent events can be used to provide an expression for $P_{\text {no }}$

$$
P_{\mathrm{no}}(T)=\exp \left[-\int_{0}^{T} \frac{\mathrm{d} \lambda_{\mathrm{t}}}{\mathrm{d} t}(t) Z_{\mathrm{i}}^{(n)}(T-t) \mathrm{d} t\right]
$$

where $Z_{\mathrm{i}}^{(n)}(T-t)$ is the measure of the interaction zone at $t$ for a defect that would break at $T$. At the beginning of loading, no interactions occur and $\lambda_{b}(T) \simeq \lambda_{t}(T)$ and as inore and more defects nucleate $\lambda_{b}(T) \ll \lambda_{t}(T)$. It is expected that the density of broken flaws saturates when $T \rightarrow \infty$ even though the total density of flaws able to break may approach infinity. Equation (4) can be derived by using results of mathematical morphology. The probability of being in a non-obscured zone $\left(P_{\mathrm{no}}\right)$ is expressed through the mean obscuration zone $\mathscr{M}^{(n)}(T)$. This zone is calculated by averaging at time $T$ the section of the obscured zones $Z_{i}^{(n)}(T-t)$ for a nucleation at time $t$ and with density $\frac{1}{\lambda_{t}(T)} \frac{\mathrm{d} \lambda_{\mathrm{t}}}{\mathrm{d} t}(t)$. The mean obscuration zone can then be expressed as

$$
\mathscr{M}^{(n)}(T) \lambda(T)=\int_{0}^{T} \frac{\mathrm{d} \lambda_{l}}{\mathrm{~d} t}(t) Z_{i}^{(n)}(T-t) \mathrm{d} t
$$

so that

$$
P_{\mathrm{no}}(T)=\exp \left[-\mathscr{M}^{(n)}(T) \lambda_{\mathrm{t}}(T)\right]
$$

Equation (6) is the result obtained for the boolean islands model (Serra, 1982).

\section{Applications}

Usually, the interaction zone cannot be assumed as a time-constant variable and since no analytical expressions are available for $Z_{i}^{(n)}$, an approximation will be proposed. The shape of the interaction zone is supposed to be constant, i.e., all the interaction zones are self-similar (Bluhm, 1969; Freund, $1972)$ and $Z_{i}^{(n)}$ can be written as

$$
Z_{i}^{(n)}(T-t)=[k C(T-t)]^{n} \quad \text { with } \quad n=1,2,3
$$

where $k \in] 0,1]$ is a shape parameter, $C$ the longitudinal stress wave velocity so that $k C(T-t)$ is a representative length of the relaxation zone around a broken flaw. The static description of fracture in brittle materials can be given by a two-parameter Weibull model. The mean number of flaws able to break for a stress less than or equal to $\sigma$ is then assumed to follow a power law function

$$
\mu_{\mathrm{t}}\left(T, Z^{(n)}\right)=\frac{Z^{(n)}}{Z_{0}^{(n)}}\left[\frac{\sigma(T)}{S_{0}}\right]^{m}
$$

where $m$ is the Weibull modulus and $S_{0}$ the scale parameter relative to the measure of a reference zone $Z_{0}^{(n)}$.

When dynamic loadings are considered with a constant stress rate $\mathrm{d} \sigma / \mathrm{d} t=\dot{\sigma}$, one can define a dimensionless flaw density $\left(\overline{\hat{\lambda}}=\lambda / \lambda_{\mathrm{c}}\right)$, time $\left(\bar{T}=T / t_{\mathrm{c}}\right)$, space measure $\left(\bar{Z}^{(n)}=Z^{(n)} / Z_{\mathrm{c}}^{(n)}\right)$ and stress $\left(\bar{\sigma}=\sigma / \sigma_{\mathrm{c}}\right)$ from the condition

$$
\lambda_{\mathrm{c}} Z_{\mathrm{c}}^{(n)}=1 \quad \text { with } \quad \lambda_{\mathrm{c}}=\lambda_{\mathrm{t}}\left(t_{\mathrm{c}}\right) \text { and } Z_{\mathrm{c}}^{(n)}=Z_{\mathrm{i}}^{(n)}\left(t_{\mathrm{c}}\right)
$$


where the subscript $c$ denotes characteristic quantities. A characteristic stress can be defined by $\sigma_{\mathrm{c}}=\dot{\sigma} t_{\mathrm{c}}$. Equation (9) expresses the fact that the characteristic zone of measure $Z_{\mathrm{c}}^{(n)}$ contains a unique flaw that may break at the characteristic time $t_{c}$.

\subsection{Fragmentation analysis}

By using equations (3), (4), (7) and (8) an analytical solution is proposed for the differential equation (3) in the case of a constant stress rate $\dot{\sigma}$ :

$$
\bar{\lambda}_{\mathrm{b}}(\bar{T})=\frac{m}{m+n}\left(\begin{array}{c}
m+n \\
m
\end{array}\right) \gamma\left[\frac{m}{m+n}, \frac{\bar{T}^{m+n}}{\left(\begin{array}{c}
m+n \\
m
\end{array}\right)}\right]
$$

where $\gamma$ is the incomplete gamma function and $\left(\begin{array}{c}m+n \\ m\end{array}\right)$ a binomial coefficient. The dimensionless density of broken flaws at saturation $\bar{\lambda}_{b}(\infty)$ can be derived from equation (10) and is only dependent on the Weibull modulus $m$ and the space dimension $n$. Figure 4 shows an increase of the number of broken flaws at saturation with the Weibull modulus $m$.

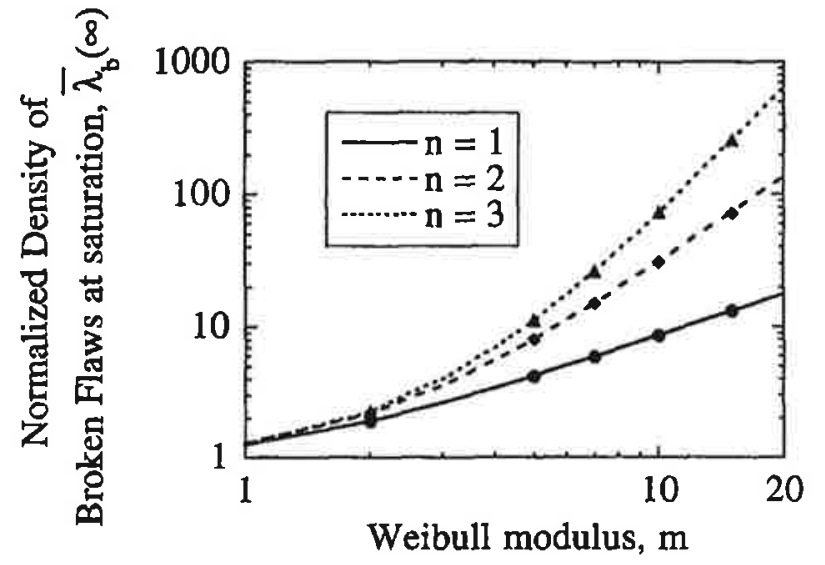

Fig. 4. - Normalized density of broken flaws at saturation versus Weibull modulus for different values of the space dimension $n$. The solid symbols show results obtained by Monte-Carlo simulations.

Fig. 4. - Evolution de la densité normée de défauts cassés en fonction du module de Weibull pour différentes valeurs de la dimension de l'espace $n$. Les symboles pleins correspondent à des résultats de simulations par la méthode de Monte-Carlo.

An explanation for this phenomenon can be proposed by using equation (3). With a high Weibull modulus $m$, the density of defects will increase dramatically in a small time step when the stress $\sigma$ becomes larger than $S_{0}$. Because of the time dependence of the saturation mechanism, many defects nucleate before any significant saturation and the material will be fully fragmented. If $m$ is small, there is much more time between two crack initiations. The first nucleated defects can then obscure others before their own nucleation and only few defects eventually nucleate. Lastly, the error between the Monte-Carlo simulations (300 realizations per computation) for a zone of measure $\bar{Z}^{(n)}=100$ and the solution at saturation given in equation (10) is less than $0.5 \%$ (fig. 4).

\subsection{Damage evolution law}

The variable $P_{\text {no }}$ can be used to define a damage variable in the framework of Continuum Damage Mechanics, even if $P_{\text {по }}$ describes a non-homogeneous stress-field due to the randomness of fragmentation. By averaging over a representative zone (to be specified later), $1-P_{\text {no }}$ is equal to 
the damage variable $D$, with $D=0$ for the virgin material and $D=1$ for the fully broken one. It is interesting to notice that the first-order approximation of equation (4) leads to the differential equation proposed by Grady and Kipp (1980) to describe the evolution of a damage variable. By using equations (4) and (7), the evolution law of the damage variable $D$ can be written as

$$
\frac{\mathrm{d}^{n-1}}{\mathrm{~d} t^{n-1}}\left(\frac{1}{1-D} \frac{\mathrm{d} D}{\mathrm{~d} t}\right)=\lambda_{\mathrm{t}}(t) n !(k C)^{n}
$$

An expression for the damage parameter $D$ can be derived by integrating equation (11) in the case of a constant stress rate $\sigma$ :

$$
D=1-\exp \left[-\frac{(\bar{\sigma})^{m+n}}{\left(\begin{array}{c}
m+n \\
m
\end{array}\right)}\right] .
$$

Equation (12) shows that $D(\bar{T}=1) \cong 0$ and $D(\bar{T}=2) \cong 1$ (i.e., most of the damage evolution occurs during a time interval equal to $t_{\mathrm{c}}$ ). During $t_{\mathrm{c}}$, the measure of the horizon is limited by $Z_{\mathrm{i}}^{(n)}\left(t_{\mathrm{c}}\right)=Z_{\mathrm{c}}^{(n)}$ so that the minimum measure of the representative zone is $Z_{\mathrm{c}}^{(n)}$. By noting that the applied stress $\Sigma$ is related to the local (or effective) stress $\sigma$ by $\sigma=\Sigma /(1-D)$, the ultimate strength $(\mathrm{d} \Sigma / \mathrm{d} \sigma=0)$ is denoted by $\Sigma_{\max }$ and is expressed as

$$
\frac{\Sigma_{\max }}{\sigma_{\mathrm{c}}}=\left[\frac{\left(\begin{array}{c}
m+n \\
m
\end{array}\right)}{m+n}\right]^{\frac{1}{m+n}} \exp \left(-\frac{1}{m+n}\right) .
$$

It is worth noticing that the normalized ultimate strength only depends upon the Weibull parameter $m$ and the space dimension $n$. The ultimate strength $\Sigma_{\max }$ is then proportional to $(\sigma)^{n /(m+n)}$.

\section{References}

Bluhm J. I., 1969. Fracture Arrest, V, 1-63, in Fracture, H. Liebowitz (ed.), Academic Press, New York, USA.

Freund L. B., 1972. Crack Propagation in an Elastic Solid Subjected to General Loading - Constant Rate of Extension, J. Mech. Phys. Solids, 20, 129-140.

Grady D. E., Klpp M. E., 1980. Continuum Modeling of Explosive Fracture in Oil Shale, Int. J. Rock Min. Sci. \& Geomech. Abstr. 17, 147-157.

Jeulin D., 1985. Anisotropic Rough Surface Modeling by Random Morphological Functions, in Proc. 4th Symp. on Stereology, Göteborg (Sweden) and 1987, Acta Stereol., 6, 183-189.

Serra J., 1982. Image Analysis and Mathematical Morphology, Academic Press, London (UK). 